\title{
Análise do Grau de Aderência à Lei de Responsabilidade Fiscal e à Lei de Acesso à Informação nos Municípios do Estado do Rio Grande do Sul com Mais de 50 Mil Habitantes
}

\author{
Élida Elis Michel Vieira ${ }^{1}$ \\ Márcia Bianchi ${ }^{2}$ \\ Clóvis Antônio Kronbauer ${ }^{3}$ \\ http://dx.doi.org/10.21527/2237-6453.2017.41.131-163 \\ Recebido em: 12/1/2016 \\ Aceito em: 7/12/2016
}

\section{Resumo}

A transparência na Contabilidade Aplicada ao Setor Público visa a disponibilizar ao cidadão informações às quais ele deve ter acesso por direito. Com base na Lei de Responsabilidade Fiscal (LRF), que busca responsabilidade na gestão fiscal, e na Lei de Acesso à Informação (LAI), que incentiva o controle social, o objetivo desta pesquisa é analisar o grau de transparência dos municípios do Rio Grande do Sul com mais de 50 mil habitantes. Quanto aos procedimentos metodológicos, esta pesquisa é classificada como quantitativa, descritiva e documental. Durante os meses de setembro e outubro de 2014 , foram utilizados indicadores de conformidade com as duas leis mencionadas para coletar

1 Graduada do curso de Ciências Contábeis da Universidade Federal do Rio Grande do Sul (UFRGS). elidaelis@gmail.com

2 Doutora em Economia do Desenvolvimento pela Universidade Federal do Rio Grande do Sul (UFRGS). Mestre em Ciências Contábeis pela Universidade do Vale do Rio dos Sinos (Unisinos). Graduada em Ciências Contábeis pela Universidade Regional Integrada do Alto Uruguai e das Missões (URI). Professora do Programa de Pós-Graduação em Controladoria e Contabilidade da Universidade Federal do Rio Grande do Sul (UFRGS). marcia.bianchi@ufrgs.br

3 Doutor em Contabilidade e Auditoria pela Universidade de Sevilla, reconhecido pela Universidade de São Paulo (USP). Mestre em Ciências Contábeis pela Universidade do Vale do Rio dos Sinos (Unisinos). Graduado em Ciências Contábeis pela Fundação Alto Taquari de Ensino Superior (Fates). Professor do Programa de Pós-Graduação em Ciências Contábeis (Unisinos). clovisk@unisinos.br 
informações disponibilizadas pelos 40 municípios do Estado com mais de 50 mil habitantes, que disponibilizaram Portal da Transparência na internet. Os resultados obtidos demonstram que muitas informações relevantes acerca do orçamento e execução orçamentária não têm sido divulgadas, e, quando disponibilizadas, muitas não atendem aos critérios de clareza e tempestividade. A Mesorregião Sudeste Rio-Grandense apresentou o maior grau de transparência, com Índice de Conformidade Geral Médio igual a 75,56\%. Já a Mesorregião Sudoeste Rio-Grandense, com IC Geral Médio de 51,11\%, foi considerada a menos transparente. Em relação à LRF, a informação menos divulgada foi o Parecer Prévio de Prestação de Contas. Quanto à LAI, o quesito acessibilidade foi o menos pontuado pelos municípios. Sendo assim, observou-se que ainda falta fiscalização quanto ao cumprimento das leis em questão, impossibilitando 0 acesso livre do cidadão às informações públicas, bem como sua participação ativa no processo de controle social.

Palavras-chave: Contabilidade aplicada ao setor público. Transparência. Lei de Responsabilidade Fiscal. Lei de Acesso à Informação.

\title{
ANALYSIS OF THE ADHERECE DEGREE TOWARDS THE FISCAL RESPOSABILITY LAW AND INFORMATION ASSESSMENT LAW IN CITIES OF THE STATE OF RIO GRANDE DO SUL WITH MORE THAN 50 THOUSAND INHABITANTS
}

\begin{abstract}
The transparency in Applied Accounting to the Public Sector seeks to provide information which allows the citizens to have access to their rights. The objective of this research is to analyse the transparency degree in cities of Rio Grande do Sul with more than fifty thousand inhabitants based on the Fiscal Responsibility Law (FRL) - which aims the responsibility in fiscal management and on the Information Assessment Law (IAL) - which prompts the social control. As far as for the methodological procedures, this is classified as a quantitative, qualitative and documental research whereas, during the months of September and October of 2014, conformity indicators were used with the both laws mentioned in order to collect information available by the 40 cities of the State with more than 50 thousand inhabitants - which offered the Transparency Portal on the internet. The results gained show that much of the relevant information concerning budget and budget execution has not been presented as well as the lack of clarity and quality criteria when available. The Southeast Mesoregion of Rio Grande do Sul brought up the highest degree of transparency, with the Average General Conformity Index equaling 75,56\%. However, the Southeast Mesoregion Sudoeste of Rio Grande do Sul - with the Average General $\mathrm{Cl}$ of $51,11 \%$, ended up being the least transparent one. Regarding the $\mathrm{FRL}$, the least shown information was the Prior Report. As for the IAL, the acessibility query was the least punctuated by the counties. Therefore, it was observed that fiscalization is still missing when the laws compliance was required, making it difficult for the citizens to get public information, as well as their active participation on social control process.
\end{abstract}

Keywords: Applied accounting to the public sector. Transparency. Fiscal Responsibility Law. Information Assessment Law. 
O Estado existe para defender os bens e interesses de uma coletividade. Decorre da autoridade máxima exercida pelo Estado dentro do seu território o seu dever de legislar sobre as regras cotidianas da população, a fim de corrigir o que estiver errado e manter a ordem social (SILVA, 2011). A Contabilidade Pública, atualmente denominada de Contabilidade Aplicada ao Setor Público, é responsável por captar, registrar, acumular, resumir e interpretar todos os fenômenos que têm interferência no orçamento, finanças e patrimônio dos entes públicos. Na Contabilidade Aplicada ao Setor Público, as movimentações contábeis devem ser passíveis de acompanhamento a qualquer momento, desde o seu início, sendo organizadas de forma que seu acesso seja facilitado (KOHAMA, 2009).

Sendo o Estado formado para o povo e a Administração Pública obrigada a ser cada vez mais transparente, informando os atos dos gestores de forma clara e inteligível, para que os cidadãos compreendam o que é feito com o dinheiro fruto das arrecadações, surgiram a Lei de Responsabilidade Fiscal (LRF), em 2000, que foi alterada pela Lei Complementar $\mathrm{n}^{\circ} 131$, de 27 de maio de 2009, e a Lei de Acesso à Informação (LAI), em 2011.

A Lei Complementar $n^{\circ} 101$, de 4 de maio de 2000, mais conhecida como Lei de Responsabilidade Fiscal, "estabelece normas de finanças públicas voltadas para a responsabilidade na gestão fiscal" (BRASIL, 2000). Ela visa a regular a forma como o recurso público é empenhado, definindo planos orçamentários que devem ser desenvolvidos anualmente pela Administração Pública, com o intuito de ampliar a responsabilidade e a transparência na gestão dos gastos públicos. A LRF foi alterada pela chamada Lei da Transparência - a Lei Complementar $n^{\circ} 131$-, que acrescentou a sua redação a exigência de que informações pormenorizadas referentes à execução orçamentária e financeira sejam disponibilizadas em tempo real, em meio eletrônico que possibilite amplo acesso público (BRASIL, 2009). 
Já a Lei ${ }^{\circ} 12.527$, de 18 de novembro de 2011, denominada de Lei de Acesso à Informação, define que informações de interesse público devem ser divulgadas, sem que haja necessidade de solicitação antes, de forma espontânea, pela Administração Pública, que deve, inclusive, incentivar o controle social (BRASIL, 2011).

Com base nessas leis, anualmente metas são traçadas e divulgadas pelos gestores públicos, objetivando definir as prioridades e estratégias para os anos seguintes da Administração. Uma análise do grau de adesão às referidas leis constitui-se relevante a partir do momento em que a divulgação das mesmas e do quanto os municípios as têm cumprido, encarrega-se de incentivar o controle social, imprescindível para a evolução da Administração Pública e da sociedade como um todo.

Sendo assim, esta pesquisa visa a responder à seguinte questão: Qual o grau de adesão às exigências da Lei de Responsabilidade Fiscal e da Lei de Acesso à Informação nos municípios com mais de 50 mil habitantes do Estado do Rio Grande do Sul? Desta forma, o objetivo do estudo é verificar se os municípios do Estado do Rio Grande do Sul com mais de 50 mil habitantes têm cumprido as exigências da Lei de Responsabilidade Fiscal e da Lei de Acesso à Informação.

O estudo está organizado, além desta introdução, com uma base teórica envolvendo o tema. Na terceira seção são relatados os procedimentos metodológicos utilizados e, na seção quatro, são descritos e analisados os dados obtidos. Por fim, na quinta seção, são apresentadas as considerações finais acerca do estudado e sugeridas abordagens para estudos futuros.

\section{Referencial Teórico}

Nesta seção são abordados os conceitos relacionados à Contabilidade Aplicada ao Setor Público, Normas Brasileiras de Contabilidade, Lei de Responsabilidade Fiscal e Lei de Acesso à Informação, além de outros trabalhos publicados na temática. 


\section{Contabilidade Aplicada ao Setor Público}

A Contabilidade Aplicada ao Setor Público (Casp) é responsável pelo registro, controle e demonstração dos atos da Administração Pública. Kohama (2009) define esse ramo da contabilidade como um dos mais complexos da ciência contábil, que tem por objetivo captar, registrar, acumular, resumir e interpretar todos os fenômenos que afetam o orçamento, as finanças e o patrimônio das entidades de direito público interno, ou seja, União, Estados, Distrito Federal e municípios e respectivas autarquias.

Ainda, a Casp é "o ramo da ciência contábil que aplica, no processo gerador de informações, os Princípios Fundamentais de Contabilidade e as normas contábeis direcionados ao controle patrimonial de entidades do setor público" (CONSELHO..., 2012, p. 7). Ela, "ao refletir, sistematicamente, o ciclo da Administração Pública para evidenciar informações necessárias à tomada de decisões, à prestação de contas e à instrumentalização do controle social, exerce sua função social" (SILVA; BIANCHI; VENDRUSCOLO, 2014, p. 195).

As normas gerais aplicadas à Casp estão instituídas pela Lei $\mathrm{n}^{\circ}$ 4.320/1964. Ela regulamenta a Contabilidade Aplicada ao Setor Público, firmando normas gerais para elaboração e controle dos orçamentos públicos. O seu artigo 77 destaca a importância da função de controle, que deve ser desenvolvida a fim de que as contas públicas sejam facilmente acompanhadas de forma prévia, concomitante e subsequente aos atos e fatos da Administração (BRASIL, 1964).

As normas referentes à Contabilidade Aplicada ao Setor Público compõem as Normas Brasileiras de Contabilidade-NBC-NBC 16 (NBCs 16.1 a 16.11), que visa à convergência dos preceitos que regem a Contabilidade Pública aos padrões internacionais. De acordo com definição da NBC 16, a Casp tem o objetivo de fornecer informações sobre receitas e despesas 
alcançadas, sobre o patrimônio da entidade pública e suas mutações, realizar adequada prestação de contas e, inclusive, incentivar o controle social. O objeto da Casp é o patrimônio público (CONSELHO..., 2012).

Assim, a prestação de contas e da transparência e o direito à informação são fortalecidos pelo acesso à informação como um pré-requisito para garantir a voz e a participação necessárias para uma sociedade democrática e transparente (KIERKEGAARD, 2009).

\section{Lei de Responsabilidade Fiscal}

A Lei de Responsabilidade Fiscal (LRF) visa a impor maior responsabilidade na gestão fiscal, sendo obrigatório à União, aos Estados, ao Distrito Federal e aos municípios o desenvolvimento de planejamentos prévios de receitas e realização de despesas públicas, a fim de aprimorar o emprego dos recursos públicos (BRASIL, 2000). Segundo Kraemer (2003, p. 20), a LRF “entrou no cenário da administração pública brasileira (...) com a finalidade de disciplinar a gestão de recursos públicos, atribuindo mais responsabilidade a seus gestores". Assim, ela introduziu "inovações na administração das finanças públicas, instituindo mecanismos de transparência fiscal e controle social dos gastos públicos" (SILVA; BIANCHI; VENDRUSCOLO, 2014, p. 195).

A Lei Complementar $\mathrm{n}^{\circ} 131$ acrescentou dispositivos à LRF, alterando a redação de dois de seus artigos, com o fim de assegurar a transparência por meio do incentivo à participação popular no desenvolvimento dos planos e metas orçamentários e do livre-acesso da população ao emprego de receitas e despesas. O texto também definiu prazos para que os municípios atendam as suas exigências: 1 ano (a partir da sua publicação) para a União, o Distrito Federal e os municípios com mais de 100.000 habitantes, 2 anos para os municípios que têm entre 50.000 e 100.000 habitantes, e 4 anos para os que têm até 50.000 habitantes (BRASIL, 2009). 
Para fins de definição de metas, diretrizes e prioridades da Administração Pública, foi desenvolvido o Sistema Orçamentário, que é composto pelo Plano Plurianual (PPA), pela Lei das Diretrizes Orçamentárias (LDO) e pela Lei Orçamentária Anual (LOA). A gestão fiscal eficiente se dá por meio da execução desses planos, tendo em vista que sua aplicação proporciona maior transparência e responsabilidade na gestão dos recursos públicos.

\section{Lei De Acesso À Informação}

A Lei de Acesso à Informação (LAI) tem o objetivo de regulamentar dispositivos já existentes na Constituição brasileira, que prevê, por exemplo, no seu artigo $5^{\circ}$ :

todos têm direito a receber dos órgãos públicos informações de seu interesse particular, ou de interesse coletivo ou geral, que serão prestadas no prazo da lei, sob pena de responsabilidade, ressalvadas aquelas cujo sigilo seja imprescindível à segurança da sociedade e do Estado (BRASIL, 1988).

Submetem-se à LAI a União, os Estados, o Distrito Federal e os municípios, para garantir aos cidadãos o direito de conhecer a parcela de recursos auferidos e seu respectivo emprego pela Administração Pública (BRASIL, 2011).

Em cartilha elaborada pela Controladoria Geral da União (CGU), encontra-se a seguinte definição: "A Lei 12.527 representa uma mudança de paradigma em matéria de transparência pública, pois estabelece que o acesso é regra e o sigilo, exceção". (CONTROLADORIA..., 2011, p. 4). A partir daí, qualquer cidadão que tiver interesse pode solicitar acesso às contas públicas, desde que não sejam sigilosas, respeitando regras e prazos para obtenção das informações. 
De acordo com o artigo $8^{\circ}$ da LAI, os órgãos e entidades públicos têm o dever de promover as informações públicas em local de fácil acesso, independentemente da solicitação dos cidadãos (BRASIL, 2011). Isto é, a divulgação das contas não deve ficar restrita às solicitações, e as informações devem estar disponíveis em portais eletrônicos oficiais da Administração Pública, sendo amplamente divulgadas. Os dados que não forem expostos podem ser solicitados pelos cidadãos com interesse em informações adicionais.

\section{Estudos Relacionados}

Kraemer (2003) demonstrou a aplicação e importância da LRF e do profissional contábil junto aos gestores de órgãos públicos. Segundo a autora, a Contabilidade é a ciência responsável pela produção de informações, que, esquecida por muitas entidades, deve ser reorganizada, bem como seus controles internos e administrativos, a fim de demonstrar com transparência todos os fatos relevantes a ela relacionados. Kraemer defende que a Lei Complementar somente será efetiva se cada esfera do governo dispuser de corpo técnico capacitado a cumprir suas exigências, composto por profissionais de variadas áreas, inclusive da área contábil. Sendo assim, conclui que o profissional contábil deve estar preparado para repassar as informações relevantes ao administrador público e assessorá-lo nas tomadas de decisão presentes e futuras.

Cruz et al. (2012) analisaram portais eletrônicos dos maiores municípios brasileiros com a intenção de verificar seu nível de transparência nas informações acerca da gestão pública. Concluíram que os municípios não estão divulgando de forma completa as informações necessárias, sendo os níveis de transparência considerados baixos e incompatíveis com o grau de desenvolvimento socioeconômico dos municípios.

Em Silva (2013) foi verificado o grau de aderência dos municípios mato-grossenses às exigências requeridas pela LAI e pela LRF. O estudo foi realizado com base na aplicação de 32 indicadores, de acordo com as 
exigências constantes nas duas leis. Foram analisados 56 municípios com mais de 10 mil habitantes, e o estudo mostrou que, dentro dessa amostra, ainda é baixa a aderência aos preceitos da LAI e da LRF, e que os gestores públicos subutilizam os recursos de evidenciação de informações na internet, sendo a divulgação de informações ainda precária.

Já Viana et al. (2013) avaliaram a aderência aos critérios internacionais de transparência, verificando se as contas públicas do município de Manaus estavam sendo divulgadas e apresentadas de forma adequada. Identificaram baixo nível de divulgação de informações no Portal da Transparência do Município, observando que aproximadamente 52\% dos critérios exigidos eram atendidos. Os autores concluíram que "a governança eletrônica e a responsabilização governamental, núcleo da definição de accountability, expressavam informações fracas para o cidadão usuário”.

Leite Filho, Andrade e Colares (2014) verificaram o nível de transparência da gestão fiscal pública nas seis cidades mais populosas de Minas Gerais. Os autores descobriram que o nível de transparência estava relacionado à população de cada município e ao índice de desenvolvimento econômico e social no qual se encontravam. Os resultados obtidos apontaram para um nível de transparência fiscal ainda precário, tendo em vista que muitas informações encontradas nos Portais da Transparência eram defasadas, não pormenorizadas, indisponíveis e de difícil localização e entendimento.

\section{Procedimentos Metodológicos}

No que diz respeito à abordagem do problema, esta pesquisa se classifica como quantitativa, pois traduz em números as informações relevantes quanto à transparência na gestão pública municipal (RAUPP; BEUREN, 2013). Quanto aos seus objetivos, a pesquisa é caracterizada como descritiva, pois tem o intuito de descrever o quanto os municípios do Rio Grande do Sul têm sido transparentes, por meio do cumprimento das leis em questão (GIL, 2008). Com base nos procedimentos técnicos utilizados, o estudo pode 
ser classificado como pesquisa documental (GIL, 2008). Para a realização do estudo foram utilizadas informações disponibilizadas pelos municípios em seus portais eletrônicos, caracterizadas, portanto, como fontes primárias.

A população da pesquisa é composta pelos 497 municípios existentes no Estado do Rio Grande do Sul, e a definição da amostra analisada foi feita com base em dados do IBGE (INSTITUTO..., 2010), que apresentou 42 municípios no Estado com mais de 50 mil habitantes. Os municípios de Viamão e Sapiranga, contudo, foram desconsiderados, haja vista que seus "Portais da Transparência" (locais onde são disponibilizadas informações referentes ao planejamento e execução orçamentários) estiveram "em manutenção" durante o período de coleta de dados. Dessa forma, a amostra ajustada é composta por 40 municípios, e foi separada por mesorregiões, conforme mostra o Quadro 1.

\section{Quadro 1 - Municípios da amostra divididos por mesorregiões}

\begin{tabular}{|l|l|}
\hline \multicolumn{1}{|c|}{ Mesorregião } & \multicolumn{1}{c|}{ Municípios } \\
\hline Centro Ocidental Rio-Grandense & Santa Maria \\
\hline Centro Oriental Rio-Grandense & $\begin{array}{l}\text { Santa Cruz do Sul, Venâncio Aires, Lajeado, Cachoeira } \\
\text { do Sul }\end{array}$ \\
\hline Metropolitana de Porto Alegre & $\begin{array}{l}\text { Montenegro, Taquara, Alvorada, Cachoeirinha, } \\
\text { Campo Bom, Canoas, Esteio, Gravataí, Guaíba, Novo } \\
\text { Hamburgo, Parobé, Porto Alegre, São Leopoldo, } \\
\text { Sapucaia do Sul, Camaquã }\end{array}$ \\
\hline Nordeste Rio-Grandense & Vacaria, Bento Gonçalves, Caxias do Sul, Farroupilha \\
\hline Noroeste Rio-Grandense & $\begin{array}{l}\text { Passo Fundo, Santa Rosa, Erechim, Santo Ângelo, } \\
\text { Ijuí, Carazinho, Cruz Alta }\end{array}$ \\
\hline Sudeste Rio-Grandense & Rio Grande, Canguçu, Pelotas \\
\hline Sudoeste Rio-Grandense & $\begin{array}{l}\text { Santana do Livramento, São Gabriel, Bagé, Alegrete, } \\
\text { São Borja, Uruguaiana }\end{array}$ \\
\hline
\end{tabular}

Fonte: Elaborado a partir de INSTITUTO..., 2010.

No que se refere à coleta dos dados, o presente estudo utilizou indicadores de conformidade, adaptados de Silva (2013), Brasil (2000) e Brasil (2011), para verificar se o que está disposto na LRF e na LAI está sendo 
executado pelos municípios. Foram estabelecidos 15 indicadores acerca das disposições da LRF e 15 referentes à LAI, totalizando 30 indicadores, conforme o Quadro 2.

\section{Quadro 2 - Indicadores de conformidade da LRF e da LAI}

\begin{tabular}{|c|c|c|c|c|c|}
\hline Item & $\begin{array}{l}\text { Base } \\
\text { Legal }\end{array}$ & $\begin{array}{c}\text { Indicadores de } \\
\text { Conformidade LRF }\end{array}$ & IItem & $\begin{array}{l}\text { Base } \\
\text { Legal }\end{array}$ & $\begin{array}{c}\text { Indicadores de } \\
\text { Conformidade LAI }\end{array}$ \\
\hline 1 & Art. 48 & $\begin{array}{l}\text { Plano Plurianual } \\
\text { (PPA) vigente }\end{array}$ & 1 & Art. $5^{\circ}$ & $\begin{array}{l}\text { Informação disponibilizada } \\
\text { de forma transparente, clara } \\
\text { e em linguagem de fácil } \\
\text { compreensão }\end{array}$ \\
\hline 2 & Art. 48 & $\begin{array}{l}\text { Planos Plurianuais } \\
\text { (PPAs) anteriores }\end{array}$ & 2 & Art. $7^{\circ}$ & $\begin{array}{l}\text { Orientação sobre os } \\
\text { procedimentos para solicitação } \\
\text { de informação }\end{array}$ \\
\hline 3 & Art. 48 & $\begin{array}{l}\text { Lei de Diretrizes } \\
\text { Orçamentárias (LDO) } \\
\text { vigente }\end{array}$ & 3 & Art. $8^{\circ}$ & $\begin{array}{l}\text { Informações quanto as suas } \\
\text { competências }\end{array}$ \\
\hline 4 & Art. 48 & $\begin{array}{l}\text { Leis de Diretrizes } \\
\text { Orçamentárias } \\
\text { (LDOs) anteriores }\end{array}$ & 4 & Art. $8^{\circ}$ & $\begin{array}{l}\text { Informações quanto à estrutura } \\
\text { organizacional }\end{array}$ \\
\hline 5 & Art. 48 & $\begin{array}{l}\text { Lei Orçamentária } \\
\text { Anual (LOA) vigente }\end{array}$ & 5 & Art. $8^{\circ}$ & $\begin{array}{l}\text { Divulgação de endereços e } \\
\text { telefones }\end{array}$ \\
\hline 6 & Art. 48 & $\begin{array}{l}\text { Leis Orçamentárias } \\
\text { Anuais (LOAs) } \\
\text { anteriores }\end{array}$ & 6 & Art. $8^{\circ}$ & $\begin{array}{l}\text { Divulgação de horários de } \\
\text { atendimento ao público }\end{array}$ \\
\hline 7 & Art. 48 & $\begin{array}{l}\text { Relatório Resumido } \\
\text { da Execução } \\
\text { Orçamentária (RREO) }\end{array}$ & 7 & Art. $8^{\circ}$ & $\begin{array}{l}\text { Informações relativas a } \\
\text { repasses ou transferências de } \\
\text { recursos financeiros }\end{array}$ \\
\hline 8 & Art. 48 & $\begin{array}{l}\text { Relatório de Gestão } \\
\text { Fiscal (RGF) }\end{array}$ & 8 & Art. $8^{\circ}$ & Informações sobre as despesas \\
\hline 9 & Art. 48 & $\begin{array}{l}\text { Versão simplificada do } \\
\text { RREO }\end{array}$ & 9 & Art. $8^{\circ}$ & $\begin{array}{l}\text { Informações sobre licitações, } \\
\text { editais e seus resultados e } \\
\text { demais contratos celebrados }\end{array}$ \\
\hline 10 & Art. 48 & $\begin{array}{l}\text { Versão simplificada } \\
\text { do RGF }\end{array}$ & 10 & Art. $8^{\circ}$ & $\begin{array}{l}\text { Informações gerais para } \\
\text { acompanhamento de } \\
\text { programas, ações, projetos e } \\
\text { obras }\end{array}$ \\
\hline 11 & Art. 48 & $\begin{array}{l}\text { Relatório de prestação } \\
\text { de contas }\end{array}$ & 11 & Art. $8^{\circ}$ & $\begin{array}{l}\text { Disponibilização de "respostas } \\
\text { e perguntas" mais frequentes } \\
\text { da sociedade }\end{array}$ \\
\hline 12 & Art. 48 & $\begin{array}{l}\text { Parecer prévio de } \\
\text { prestação de contas }\end{array}$ & 12 & Art. $8^{\circ}$ & $\begin{array}{l}\text { Disponibilização de ferramenta } \\
\text { de pesquisa }\end{array}$ \\
\hline
\end{tabular}




\begin{tabular}{|c|c|l|l|l|l|}
\hline 13 & Art. 48 & $\begin{array}{l}\text { Incentivo à } \\
\text { participação popular e } \\
\text { audiências públicas na } \\
\text { elaboração e discussão } \\
\text { do PPA, LDO e LOA }\end{array}$ & 13 & Art. $8^{\circ}$ & $\begin{array}{l}\text { Permissão para gravação de } \\
\text { relatórios eletrônicos }\end{array}$ \\
\hline 14 & Art. 48 & $\begin{array}{l}\text { Informações de } \\
\text { execução orçamentária } \\
\text { e financeira em tempo } \\
\text { real }\end{array}$ & 14 & Art. $8^{\circ}$ & $\begin{array}{l}\text { Conteúdo acessível a pessoas } \\
\text { com deficiência }\end{array}$ \\
\hline 15 & $\begin{array}{l}\text { Divulgação das datas } \\
\text { de audiências públicas } \\
\text { quadrimestrais para } \\
\text { avaliação das metas } \\
\text { fiscais }\end{array}$ & 15 & Art. $9^{\circ}$ & $\begin{array}{l}\text { Serviço de Informações ao } \\
\text { Cidadão (SIC) }\end{array}$ \\
\hline
\end{tabular}

Fonte: Elaborado a partir de BRASIL (2000), BRASIL (2011) e SILVA (2013).

Quanto aos indicadores de conformidade referentes ao PPA, considerou-se "vigente" o PPA referente ao período de 2014 a 2017, e "anterior" ao período de 2010 a 2013. Em relação à LDO e à LOA, foram consideradas vigentes as leis relativas ao ano de 2014 e anteriores às de 2013.

Os dados necessários à análise foram coletados nos portais eletrônicos dos municípios durante os meses de setembro e outubro de 2014. Foram feitas pesquisas nesses portais a fim de verificar o cumprimento de cada item constante nos indicadores. Para cada indicador evidenciado foi atribuído um ponto. Por outro lado, em caso de não divulgação da informação, atribuiu-se a pontuação zero. Ao final, foram somados os pontos de cada município, podendo cada um obter, no máximo, 15 pontos em cada lei.

Para análise dos dados utilizou-se a análise de conteúdo (BARDIN, 2006) com intenção de inferir, por meio de indicadores, se as informações compulsórias estão sendo divulgadas pelos municípios em questão. Além disso, Teixeira (2003, p. 194) afirma que "a maioria das técnicas de análise (...) tem o propósito de contar a frequência de um fenômeno e procurar identificar relações entre os fenômenos, com a interpretação dos dados recorrendo a modelos conceituais definidos a priori". Foi, portanto, analisada 
a frequência com que as informações exigidas na LRF e na LAI foram disponibilizadas em portais eletrônicos dos municípios, sendo utilizadas para tal busca palavras-chave encontradas nos textos legais.

A quantidade de itens divulgados em cada município foi dividida pelo total de itens que deveriam ter sido divulgados, conforme o Quadro 2. Assim sendo, a quantidade de itens divulgada foi dividida por 15 , sendo calculados, assim, os índices de conformidade que são: Índice de Conformidade em relação à LRF (IC LRF); Índice de Conformidade em relação à LAI (IC LAI); e Índice de Conformidade Geral (IC Geral). Quanto ao IC Geral, realizou-se a soma de todos os itens divulgados e dividiram-se estes por 30. Os índices encontrados foram transformados em valores percentuais.

Posteriormente, os índices percentuais calculados foram analisados por meio de técnicas de estatística descritiva, a partir de tabelas e gráfico constantes na próxima seção.

\section{Análise dos Dados}

Para atender ao objetivo proposto e facilitar o entendimento, foi segregada essa seção em três subseções, sendo a primeira destinada à apresentação da análise geral da amostra, a segunda referente ao nível de conformidade à LRF e à LAI por mesorregião, e, por fim, na terceira subseção são apresentados os indicadores por lei em cada mesorregião.

\section{Análise Geral da Amostra}

O objetivo desta seção é apresentar os índices gerais de adesão às leis em estudo no Estado do Rio Grande do Sul (RS). Para isso, foi elaborada a Tabela 1, na qual foram relacionados os dados de estatística descritiva da amostra, considerando Índices de Conformidade a cada lei e Índice de Conformidade Geral. 
Tabela 1 - Estatística descritiva da amostra

\begin{tabular}{l|c|c|c}
\hline \multicolumn{1}{c|}{ Estatística Descritiva } & IC LRF* & IC LAI** & IC Geral*** \\
\hline Média & 54,33 & 76,50 & 65,42 \\
Erro padrão & 3,80 & 2,96 & 2,80 \\
Mediana & 60,00 & 83,33 & 66,67 \\
Modo & 73,33 & 86,67 & 86,67 \\
Desvio padrão & 24,04 & 18,73 & 17,68 \\
Variância da amostra & 577,89 & 350,97 & 312,64 \\
Curtose & $-1,28$ & 0,32 & $-0,98$ \\
Assimetria & $-0,30$ & $-0,99$ & $-0,30$ \\
Intervalo & 80,00 & 73,33 & 66,67 \\
Mínimo & 13,33 & 26,67 & 26,67 \\
Máximo & 93,33 & 100,00 & 93,33 \\
Nível de confiança $(95,0 \%)$ & 7,69 & 5,99 & 5,65 \\
\hline
\end{tabular}

Legenda: $\mathrm{IC}$ Geral = Índice de Conformidade Geral; IC LRF = Índice de Conformidade com a Lei de Responsabilidade Fiscal; IC LAI = Índice de Conformidade com a Lei Acesso à Informação.

Fonte: Elaborada pelos autores com base na pesquisa (2014).

Com base na Tabela 1 pode-se inferir que o grau de adesão à LRF e à LAI nos municípios do RS ainda é baixo, tendo em vista que a Média do Índice de Conformidade Geral ficou em 65,42\%. A Média do índice específico para conformidade à LRF é ainda menor, 54,33\%, demonstrando o quanto a divulgação do planejamento e da execução orçamentária dos municípios ainda está distante do previsto nas leis estudadas. O índice relativo à LAI apresentou melhor Média de adesão dos municípios, alcançando 76,50\% das informações que deveriam ser divulgadas espontaneamente nos portais eletrônicos.

Por outro lado, se comparados ao desempenho dos municípios estudados por Silva (2013), os resultados apresentados na Tabela 1 mostram-se melhores na amostra pesquisada, haja vista que a Mediana do IC Geral dos municípios do Mato Grosso foi de 25, e no Rio Grande do Sul de 66,67. Ainda, comparando os resultados obtidos, a maior diferença encontrada foi na Mediana do IC LAI, a mais elevada no RS, igual a 83,33, que apresentou pior desempenho nos municípios mato-grossenses, 16,67. 
Por meio do Mínimo, nota-se que tanto nos ICs LRF quanto nos ICs LAI sempre houve, ao menos, um indicador satisfeito. Para a LRF, o Mínimo foi $13,33 \%$ (um indicador, dentre os 15 ), e para a LAI, 26,67\% (2 indicadores). Com base no Máximo encontrado, percebe-se que nenhum município atendeu a todas as exigências da LRF (93,33\%). Já para a LAI, ao menos um município satisfez todas as suas exigências (100\%). No estudo de Silva (2013), o Mínimo encontrado foi 0,00 e, o Máximo, 68,75, demonstrando o baixo grau de transparência dos municípios do Mato Grosso.

Cabe ressaltar, ainda, que os resultados encontrados são superiores aos observados por Viana et al. (2013). Mesmo assim, como as normas base para esta pesquisa são de caráter obrigatório, é preocupante que nos municípios pesquisados os níveis de conformidade sejam inclusive relativamente distantes do cumprimento total.

\section{Análise de Conformidade por Mesorregião}

Nesta seção são apresentados os índices de conformidade de cada lei e geral obtidos em cada município das mesorregiões do Rio Grande do Sul. Na Tabela 2 foram relacionados os índices de conformidade do município de Santa Maria, único representante da Região Centro Ocidental Rio-Grandense.

Tabela 2 - Índices de conformidade Mesorregião Centro Ocidental

\begin{tabular}{c|l|c|c|c}
\hline $\mathbf{N}^{\mathbf{0}}$ & \multicolumn{1}{|c|}{ Município } & IC LRF \% & IC LAI \% & IC Geral \% \\
\hline 1 & Santa Maria & 53,33 & 86,67 & 70,00 \\
\hline & Média Região Centro Ocidental & $\mathbf{5 3 , 3 3}$ & $\mathbf{8 6 , 6 7}$ & $\mathbf{7 0 , 0 0}$ \\
\hline
\end{tabular}

Fonte: Elaborada a partir de dados da pesquisa (2014).

A partir da Tabela 2 percebe-se que o município de Santa Maria apresentou um índice geral de transparência de $70 \%$, superado pelo índice de conformidade à LAI, que alcançou $86,67 \%$ das exigências constantes na lei. Por outro lado, quanto à LRF, o município ainda está aquém do desejado, 
tendo em vista que apenas 53,33\% das informações compulsórias acerca do orçamento estão sendo disponibilizadas à população, índice abaixo da média do Estado, apresentada na seção anterior.

$\mathrm{Na}$ Tabela 3 foram arrolados os municípios que compõem a Mesorregião Centro Oriental Rio-Grandense: Santa Cruz do Sul, Venâncio Aires, Lajeado e Cachoeira do Sul, e seus respectivos índices de conformidade.

Tabela 3 - Índices de conformidade Mesorregião Centro Oriental

\begin{tabular}{c|l|c|c|c}
\hline $\mathbf{N}^{\mathbf{0}}$ & \multicolumn{1}{|c|}{ Município } & IC LRF \% & IC LAI \% & IC Geral \% \\
\hline 1 & Venâncio Aires & 73,33 & 100,00 & 86,67 \\
2 & Lajeado & 86,67 & 80,00 & 83,33 \\
3 & Santa Cruz do Sul & 60,00 & 73,33 & 66,67 \\
4 & Cachoeira do Sul & 66,67 & 60,00 & 63,33 \\
\hline & Média Região Centro Oriental & $\mathbf{7 1 , 6 7}$ & $\mathbf{7 8 , 3 3}$ & $\mathbf{7 5 , 0 0}$ \\
\hline
\end{tabular}

Fonte: Elaborada a partir de dados da pesquisa (2014).

Os municípios de Venâncio Aires e Lajeado se destacaram dos demais na região, apresentando ICs Geral de $86,67 \%$ e $83,33 \%$, respectivamente. Dos indicadores referentes à LAI, $100 \%$ foram satisfeitos em Venâncio Aires, que obteve 73,33\% de conformidade com a LRF. Já em Lajeado a divulgação das informações acerca da execução orçamentária superou ligeiramente as disponibilizações solicitadas pela LAI: foram $86,67 \%$ contra $80 \%$.

Santa Cruz do Sul e Cachoeira do Sul apresentaram ICs Geral individual inferior ao da Mesorregião, 66,67\% e 63,33\%, respectivamente. No primeiro, o IC LAI foi superior ao IC LRF: $73,33 \%$ contra $60 \%$, significando maior divulgação das formas de solicitação de informação em detrimento dos planos orçamentários, por exemplo. Já em Cachoeira do Sul os dois ICs, da LRF e da LAI, se mantiveram abaixo dos $70 \%$.

A Tabela 4 foi elaborada com base em informações coletadas nos 15 municípios da maior mesorregião do Estado: a Metropolitana de Porto Alegre. 
Tabela 4 - Índices de conformidade Mesorregião

Metropolitana de Porto Alegre

\begin{tabular}{c|l|c|c|c}
\hline $\mathbf{N}^{\mathbf{0}}$ & \multicolumn{1}{|c|}{ Município } & IC LRF \% & IC LAI \% & IC Geral \% \\
\hline 1 & Porto Alegre & 93,33 & 93,33 & 93,33 \\
2 & Canoas & 80,00 & 93,33 & 86,67 \\
3 & Esteio & 73,33 & 100,00 & 86,67 \\
4 & Novo Hamburgo & 86,67 & 86,67 & 86,67 \\
5 & Cachoeirinha & 73,33 & 86,67 & 80,00 \\
6 & Campo Bom & 60,00 & 100,00 & 80,00 \\
7 & São Leopoldo & 60,00 & 93,33 & 76,67 \\
8 & Gravataí & 26,67 & 93,33 & 60,00 \\
9 & Montenegro & 26,67 & 86,67 & 56,67 \\
10 & Guaíba & 60,00 & 46,67 & 53,33 \\
11 & Parobé & 20,00 & 86,67 & 53,33 \\
12 & Taquara & 26,67 & 73,33 & 50,00 \\
13 & Camaquã & 13,33 & 80,00 & 46,67 \\
14 & Alvorada & 20,00 & 53,33 & 36,67 \\
15 & Sapucaia do Sul & 13,33 & 53,33 & 33,33 \\
\hline & Média Região Metropolitana de Porto & $\mathbf{4 8 , 8 9}$ & $\mathbf{8 1 , 7 8}$ & $\mathbf{6 5 , 3 3}$ \\
\hline
\end{tabular}

Fonte: Elaborada a partir de dados da pesquisa (2014).

A partir da Tabela 4 verificou-se que há grandes disparidades entre os municípios que compõem a mesorregião apresentada, fato que também pode ser observado na maior mesorregião do Estado do Mato Grosso, estudada por Silva (2013). Sapucaia do Sul foi o município com menor grau de transparência, com IC Geral igual a 33,33\%. Em contraponto, tem-se o município de Porto Alegre, capital do Estado, com o melhor desempenho no quesito transparência, ficando com 93,33\% das informações divulgadas em conformidade com as disposições da LRF e da LAI.

Novo Hamburgo foi o segundo município que mais divulgou informações acerca da execução orçamentária: $86,67 \%$ dos indicadores da LRF foram atendidos, contra 13,33\% dos municípios que menos divulgaram: Sapucaia do Sul e Camaquã. Em terceiro lugar, Canoas, com $80 \%$ das exigências da LRF disponíveis em seu portal eletrônico. 
Em relação à LAI, os municípios com maior IC foram Campo Bom e Esteio, que disponibilizaram $100 \%$ das informações exigidas, seguidos por Canoas, Gravataí, Porto Alegre e São Leopoldo, que apresentaram 93,33\% dos indicadores estudados. Guaíba, Alvorada e Sapucaia do Sul foram os municípios que menos divulgaram informações que são de direito do cidadão: somente $46,67 \%, 53,33 \%$ e 53,33\%, respectivamente. A Tabela 5 traz informações sobre a transparência nos municípios da Mesorregião Nordeste:

Tabela 5 - Índices de conformidade Mesorregião Nordeste

\begin{tabular}{c|l|c|c|c}
\hline $\mathbf{N}^{\mathbf{0}}$ & \multicolumn{1}{|c|}{ Município } & IC LRF \% & IC LAI \% & IC Geral \% \\
\hline 1 & Caxias do Sul & 73,33 & 93,33 & 83,33 \\
2 & Bento Gonçalves & 46,67 & 86,67 & 66,67 \\
3 & Farroupilha & 20,00 & 80,00 & 50,00 \\
4 & Vacaria & 26,67 & 60,00 & 43,33 \\
\hline & Média Região Nordeste & $\mathbf{4 1 , 6 7}$ & $\mathbf{8 0 , 0 0}$ & $\mathbf{6 0 , 8 3}$ \\
\hline
\end{tabular}

Fonte: Elaborada a partir de dados da pesquisa (2014).

Dentre os municípios relacionados na Tabela 5, Caxias do Sul foi o que apresentou maior adesão às leis de Responsabilidade Fiscal e de Acesso à Informação, com IC Geral de 83,33\%. Seu IC LAI superou o geral, apresentando 93,33\% de conformidade com os dispositivos em questão. Por outro lado, pouco abaixo do índice geral do município ficou o IC LRF, com $73,33 \%$ dos indicadores atendidos.

Ainda na região Nordeste, Vacaria se destacou negativamente, apresentando o pior desempenho da mesorregião, com apenas $43,33 \%$ de informações gerais divulgadas. Quanto ao IC LRF, Farroupilha demonstrou ser o município que menos expõe seus planos e execuções orçamentários, com apenas $20 \%$ dos indicadores observados satisfeitos. Por outro lado, quanto ao IC LAI, o mesmo município apresentou boa adesão, atingindo $80 \%$ de conformidade.

Os sete municípios que compõem a Mesorregião Noroeste do Rio Grande do Sul foram relacionados na Tabela 6, bem como seus respectivos índices de conformidade. 
Tabela 6 - Índices de conformidade Mesorregião Noroeste

\begin{tabular}{c|l|c|c|c}
\hline $\mathbf{N}^{\mathbf{0}}$ & \multicolumn{1}{|c|}{ Município } & IC LRF \% & IC LAI \% & IC Geral \% \\
\hline 1 & Erechim & 80,00 & 93,33 & 86,67 \\
2 & Ijuí & 73,33 & 86,67 & 80,00 \\
3 & Passo Fundo & 80,00 & 80,00 & 80,00 \\
4 & Santa Rosa & 73,33 & 86,67 & 80,00 \\
5 & Carazinho & 46,67 & 86,67 & 66,67 \\
6 & Santo Ângelo & 33,33 & 66,67 & 50,00 \\
7 & Cruz Alta & 20,00 & 73,33 & 46,67 \\
\hline & Média Região Noroeste & $\mathbf{5 8 , 1 0}$ & $\mathbf{8 1 , 9 0}$ & $\mathbf{7 0 , 0 0}$ \\
\hline
\end{tabular}

Fonte: Elaborada a partir de dados da pesquisa (2014).

A Tabela 6 mostra que a adesão à LAI é consideravelmente maior que à LRF nos municípios da Mesorregião Noroeste, tendo em vista o resultado dos índices de conformidade médios: $81,90 \%$ e $58,10 \%$ respectivamente. $\mathrm{O}$ destaque da região é o município de Erechim, que apresentou IC Geral de $86,67 \%$, sendo $80 \%$ correspondentes à conformidade com a LRF e, 93,33\%, à LAI. Os dados mostram que Cruz Alta é o município que menos divulga informações acerca de seu planejamento orçamentário. Com IC LRF de apenas $20 \%$, a prefeitura não divulgou seus planos orçamentários, nem vigentes, nem anteriores. O desempenho referente à LAI foi mais satisfatório, tendo em vista que 73,33\% das informações compulsórias estão disponíveis no portal eletrônico do município.

Depois de Cruz Alta, Santo Ângelo e Carazinho obtiveram os piores índices médios da região: $50 \%$ e 66,67\%, que foram impactados, principalmente, pela baixa adesão às exigências da LRF. Quanto à LAI, os dois municípios apresentaram $66,67 \%$ e $86,67 \%$, respectivamente, como índices de conformidade.

Os municípios de Rio Grande, Canguçu e Pelotas, componentes da Mesorregião Sudeste, assim como seus indicadores de conformidade, formam a Tabela 7, apresentada a seguir. 
Tabela 7 - Índices de conformidade Mesorregião Sudeste

\begin{tabular}{c|l|c|c|c}
\hline $\mathbf{N}^{\mathbf{0}}$ & \multicolumn{1}{|c|}{ Município } & IC LRF \% & IC LAI \% & IC Geral \% \\
\hline 1 & Pelotas & 80,00 & 93,33 & 86,67 \\
2 & Rio Grande & 73,33 & 86,67 & 80,00 \\
3 & Canguçu & 46,67 & 73,33 & 60,00 \\
\hline & Média Região Sudeste & $\mathbf{6 6 , 6 7}$ & $\mathbf{8 4 , 4 4}$ & $\mathbf{7 5 , 5 6}$ \\
\hline
\end{tabular}

Fonte: Elaborada a partir de dados da pesquisa (2014).

A partir da Tabela 7 percebe-se que Pelotas e Rio Grande se destacaram com seus ICs Geral de 86,67 e 80\%, respectivamente. Com 93,33\% de conformidade com a LAI, Pelotas deixou de atender a somente um indicador, e a três indicadores da LRF, ficando com IC LRF de $80 \%$.

No portal eletrônico de Canguçu não foram encontrados nem os Planos Plurianuais, nem as Leis Orçamentárias, o que colaborou para o baixo desempenho do município, que obteve IC LRF igual a 46,67\%, isto é, 20 pontos percentuais abaixo da média da mesorregião.

A Tabela 8 traz informações acerca da transparência na Mesorregião Sudoeste.

Tabela 8 - Índices de conformidade Mesorregião Sudoeste

\begin{tabular}{c|l|c|c|c}
\hline $\mathbf{N}^{\mathbf{o}}$ & \multicolumn{1}{|c|}{ Município } & IC LRF \% & IC LAI \% & IC Geral \% \\
\hline 1 & Alegrete & 80,00 & 60,00 & 70,00 \\
2 & São Gabriel & 66,67 & 60,00 & 63,33 \\
3 & São Borja & 46,67 & 66,67 & 56,67 \\
4 & Uruguaiana & 60,00 & 33,33 & 46,67 \\
5 & Bagé & 46,67 & 40,00 & 43,33 \\
6 & Santana do Livramento & 26,67 & 26,67 & 26,67 \\
\hline & Média Região Sudoeste & $\mathbf{5 4 , 4 4}$ & $\mathbf{4 7 , 7 8}$ & $\mathbf{5 1 , 1 1}$ \\
\hline
\end{tabular}

Fonte: Elaborada a partir de dados da pesquisa (2014).

A região apresentada na Tabela 8 registrou o pior desempenho do Estado, com 51,11\% de IC Geral Médio, sendo o IC LRF Médio pouco superior, igual a 54,44\%, e o da LAI inferior, 47,78\%. Percebe-se que Santana do Livramento foi o município menos transparente, com apenas $26,67 \%$ das 
exigências satisfeitas, tanto na LRF quanto na LAI. Isso significa que, dos 15 indicadores aplicados em cada lei, somente 8 foram atendidos (4 na LRF e 4 na LAI). Em contrapartida, o melhor desempenho da mesorregião foi de Alegrete, que apresentou $70 \%$ de IC Geral, índice superior em relação à LRF (80\%), e pouco inferior na LAI (60\%).

Para finalizar esta seção de análise da conformidade dos municípios agrupados por mesorregião, foi elaborado o Gráfico 1, que visa a demostrar o nível de adesão de cada região às leis estudadas.

\section{Gráfico 1 - Índices de conformidade por mesorregião}

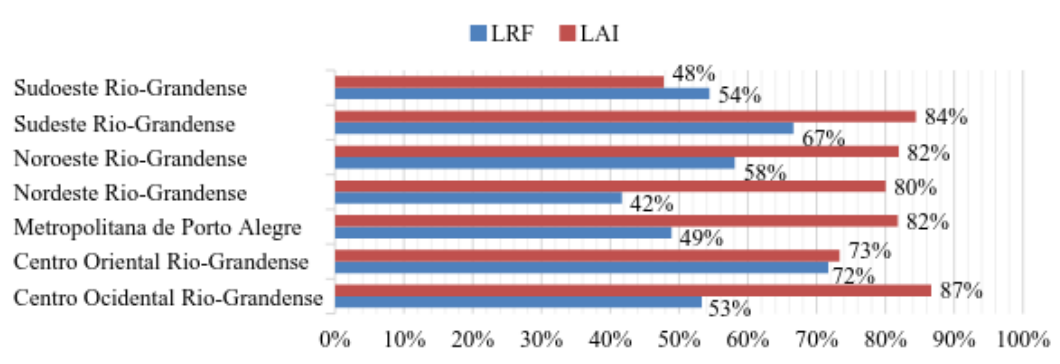

Fonte: Elaborado a partir de dados da pesquisa (2014).

Com base no Gráfico 1 pode-se inferir que o grau de adesão à LAI é maior em todas as mesorregiões, exceto no Sudoeste Rio-Grandense, que apresentou índice de conformidade com a LRF seis pontos percentuais superior. Logo, percebe-se que as informações básicas exigidas pela LAI têm sido, em sua maioria, divulgadas, ao contrário dos planos e orçamentos dos municípios, que não apresentaram adesão satisfatória à LRF.

Quando comparados aos resultados obtidos por Silva (2013), nota-se que, no Mato Grosso, o cenário é oposto, pois todas as mesorregiões apresentadas pelo autor demonstraram maior adesão aos dispositivos da LRF. O desempenho das mesorregiões rio-grandenses também se destaca, pois, embora ainda deixem a desejar em alguns municípios, trazem bons índices em linhas gerais, diferente do cenário observado no estudo relacionado. 
Os Índices de Conformidade Geral encontrados variaram de 51,11\% a $75,56 \%$, sendo o pior desempenho apresentado pela Mesorregião Sudoeste Rio-Grandense e a Mesorregião mais transparente, a Sudeste Rio-Grandense. O IC Geral Médio do Estado foi 65,42\%, composto pelos 54,33\% de conformidade com a LRF, e 76,50\% com a LAI. Ainda, dentre os 40 municípios analisados, apenas 21 apresentaram IC Geral superior ao Médio do Estado. Porto Alegre teve melhor desempenho (IC Geral de 93,33\%), e o pior ficou com Santana do Livramento, que divulgou apenas 26,67\% das informações exigidas por lei.

Como observado por Kraemer (2003), ressalta-se a importância do profissional contábil no ambiente da Administração Pública, pois o mesmo tem a função de repassar informações relevantes ao administrador público e assessorá-lo no processo de tomadas de decisão. A autora afirma que a LRF somente será efetiva se houver na Administração Pública corpo técnico capacitado, habilitado a produzir informações relevantes acerca do orçamento e execução orçamentária, informações essas que devem ser divulgadas ao cidadão, conforme exigências das leis de Responsabilidade Fiscal e de Acesso à Informação.

Cabe novamente destacar que há uma grande disparidade nos níveis de cumprimento da divulgação, tanto entre regiões quanto entre municípios dentro das regiões. É perceptível, contudo, que, em cada região, nos municípios mais populosos e de maior capacidade econômica, apareçam os melhores Índices de Conformidade, o que remete a entender que o fator recurso seja decisivo para instituir ou não melhores sistemas de informação e, consequentemente, de transparência.

\section{Análise De Conformidade Por Indicador}

Esta seção objetiva apresentar o desempenho de cada indicador observado por mesorregião estudada. Para isso, criou-se as Tabelas 9 e 10, em que foram relacionados os indicadores da LRF e da LAI utilizados no 
estudo, respectivamente, e a quantidade observada em cada mesorregião. A Tabela 9, a seguir, apresenta os indicadores empregados referentes à LRF, com o objetivo de demonstrar o percentual de adesão à lei, por indicador e por mesorregião.

Tabela 9 - Conformidade por indicador da LRF por mesorregião

\begin{tabular}{|c|c|c|c|c|c|c|c|c|c|}
\hline \multirow{2}{*}{ Indicadores } & \multicolumn{7}{|c|}{ Mesorregião* } & \multirow{2}{*}{ Total } & \multirow[t]{2}{*}{$\%$} \\
\hline & I & II & III & IV & V & VI & VII & & \\
\hline $\begin{array}{l}\text { Versão simplificada } \\
\text { do RREO }\end{array}$ & 1 & 3 & 15 & 3 & 7 & 3 & 5 & 37 & $93 \%$ \\
\hline $\begin{array}{l}\text { Versão simplificada } \\
\text { do RGF }\end{array}$ & 1 & 3 & 12 & 2 & 6 & 3 & 3 & 30 & $75 \%$ \\
\hline RGF & 1 & 4 & 10 & 2 & 5 & 2 & 5 & 29 & $73 \%$ \\
\hline PPA vigente & 1 & 4 & 7 & 2 & 6 & 2 & 5 & 27 & $68 \%$ \\
\hline $\begin{array}{l}\text { Incentivo à } \\
\text { participação popular } \\
\text { e audiências } \\
\text { públicas no processo } \\
\text { de elaboração e } \\
\text { discussão de PPA, } \\
\text { LDO e LOA }\end{array}$ & 0 & 3 & 10 & 1 & 6 & 3 & 4 & 27 & $68 \%$ \\
\hline LDO vigente & 1 & 4 & 7 & 2 & 6 & 2 & 4 & 26 & $65 \%$ \\
\hline $\begin{array}{l}\text { Informações de } \\
\text { execução orçam. e } \\
\text { financ. - tempo real } \\
\end{array}$ & 1 & 3 & 11 & 2 & 3 & 2 & 3 & 25 & $63 \%$ \\
\hline LDOs anteriores & 0 & 3 & 7 & 2 & 5 & 3 & 4 & 24 & $60 \%$ \\
\hline LOA vigente & 1 & 4 & 6 & 2 & 5 & 2 & 3 & 23 & $58 \%$ \\
\hline RREO & 1 & 4 & 5 & 2 & 3 & 3 & 4 & 22 & $55 \%$ \\
\hline LOAs anteriores & 0 & 3 & 5 & 2 & 4 & 2 & 2 & 18 & $45 \%$ \\
\hline PPAs anteriores & 0 & 2 & 6 & 1 & 3 & 1 & 4 & 17 & $43 \%$ \\
\hline $\begin{array}{l}\text { Relatório de } \\
\text { prestação de contas }\end{array}$ & 0 & 1 & 4 & 1 & 0 & 1 & 1 & 8 & $20 \%$ \\
\hline $\begin{array}{l}\text { Divulgação } \\
\text { das datas de } \\
\text { audiências públicas } \\
\text { quadrimestrais para } \\
\text { avaliação das metas } \\
\text { fiscais }\end{array}$ & 0 & 2 & 3 & 0 & 2 & 0 & 1 & 8 & $20 \%$ \\
\hline $\begin{array}{l}\text { Parecer prévio de } \\
\text { prestação de contas }\end{array}$ & 0 & 0 & 2 & 1 & 0 & 1 & 1 & 5 & $13 \%$ \\
\hline
\end{tabular}

* I = Centro Ocidental; II = Centro Oriental; III = Metropolitana; IV = Nordeste; $\mathrm{V}=$ Noroeste; $\mathrm{VI}=$ Sudeste; $\mathrm{VII}=$ Sudoeste.

Fonte: Elaborada a partir de dados da pesquisa (2014). 
Por meio desta Tabela é possível perceber que a maior parte dos indicadores obteve percentual de divulgação insatisfatório. O Relatório Resumido de Execução Orçamentária (RREO), por exemplo, que é formado pelo balanço orçamentário e deve apresentar receitas e despesas separadas por categoria econômica, foi encontrado em pouco mais da metade dos municípios. Sua versão simplificada, todavia, foi disponibilizada, em quase todos os casos, em 37 municípios. No caso do Relatório de Gestão Fiscal (RGF), 30 municípios divulgaram sua versão simplificada, enquanto 29 publicaram o relatório completo em seus sítios oficiais.

O planejamento orçamentário dos municípios, que deve ser evidenciado e amplamente divulgado em seus portais eletrônicos, é representado pelo PPA, pela LDO e pela LOA, bem como pelas suas versões de anos anteriores. Dentre os 40 municípios analisados, entretanto, somente em 27 o PPA foi divulgado, representando $68 \%$ da amostra. Já a LDO obteve $65 \%$ de adesão, estando disponível em 26 municípios. A LOA foi a menos encontrada, tendo em vista que apenas 23 municípios divulgaram seus orçamentos, conforme rege a LRF. Esses resultados corroboram com os achados de Viana et al. (2013), que destacaram a deficiência existente quanto à divulgação do orçamento ao cidadão, dificultando o controle social.

Foram consideradas como incentivo à participação popular quaisquer notícias e "chamadas" encontradas nos portais eletrônicos divulgando datas e locais das audiências públicas, relacionadas ao processo de elaboração e discussão de PPA, LDO e LOA. A adesão foi baixa, posto que a participação dos cidadãos é imprescindível para auxiliar nas tomadas de decisão acerca de prioridades dos municípios. Em $68 \%$ dos casos as audiências foram divulgadas por meio eletrônico e os cidadãos convidados a participar. Nos municípios mato-grossenses foi observado, por Silva (2013), que o incentivo à participação popular é exceção, pois apenas 5,36\% das prefeituras divulgou datas e locais de audiências públicas. 
Em relação às datas de audiências públicas quadrimestrais para avaliação das metas fiscais, o resultado encontrado no RS foi ainda pior: somente oito prefeituras convocaram a população a fazer parte da avaliação, representando $20 \%$ da amostra observada. Já no Mato Grosso, Silva (2013) observou datas das audiências em somente 8,93\% dos municípios.

A Lei da Transparência acrescentou à LRF, entre outras exigências, a obrigatoriedade de os entes públicos disponibilizarem em tempo real informações pormenorizadas acerca de sua execução orçamentária (BRASIL, 2009). A partir da Tabela 9 , entretanto, percebe-se que diversos municípios ainda ignoram essa exigência, uma vez que, dentre os 40 analisados, $15 \mathrm{ou}$ deixaram de divulgar informações sobre a execução orçamentária, ou não as disponibilizaram em tempo real. Resultado semelhante foi obtido por Leite Filho, Andrade e Colares (2014), que, quanto à divulgação da receita e da despesa em tempo real, afirmaram que os municípios mineiros investigados não vêm cumprindo satisfatoriamente as exigências da lei.

Assim como observado por Silva (2013), dentre os indicadores da LRF os dois menos divulgados foram o Relatório de Prestação de Contas e o Parecer Prévio de Prestação de Contas. Segundo informações da Tabela 9, apenas $20 \%$ dos municípios apresentaram o primeiro, contra $13 \%$ do segundo. Viana et al. (2013) também destacaram a falta de prestação de contas no portal eletrônico do município de Manaus como fator que compromete a avaliação da Administração Pública como um todo. A proposta da Tabela 10 é relacionar o desempenho dos indicadores em cada mesorregião, bem como os percentuais de conformidade obtidos. 
Tabela 10 - Conformidade por indicador da LAI por mesorregião

\begin{tabular}{|c|c|c|c|c|c|c|c|c|c|}
\hline \multirow{2}{*}{ Indicadores } & \multicolumn{7}{|c|}{ Mesorregião } & \multirow{2}{*}{ Total } & \multirow[t]{2}{*}{$\%$} \\
\hline & I & II & III & IV & V & VI & VII & & \\
\hline $\begin{array}{l}\text { Informações quanto à } \\
\text { estrutura organizacional }\end{array}$ & 1 & 4 & 15 & 4 & 7 & 3 & 6 & 40 & $100 \%$ \\
\hline $\begin{array}{l}\text { Divulgação de } \\
\text { endereços e telefones }\end{array}$ & 1 & 4 & 15 & 4 & 7 & 3 & 6 & 40 & $100 \%$ \\
\hline $\begin{array}{l}\text { Permissão para gravação } \\
\text { de relatórios eletrônicos }\end{array}$ & 1 & 4 & 15 & 4 & 7 & 3 & 5 & 39 & $98 \%$ \\
\hline $\begin{array}{l}\text { Informações sobre as } \\
\text { despesas }\end{array}$ & 1 & 4 & 15 & 4 & 7 & 2 & 5 & 38 & $95 \%$ \\
\hline $\begin{array}{l}\text { Informações sobre } \\
\text { licitações, editais e seus } \\
\text { resultados e demais } \\
\text { contratos celebrados }\end{array}$ & 1 & 4 & 14 & 4 & 7 & 3 & 4 & 37 & $93 \%$ \\
\hline $\begin{array}{l}\text { Disponibilização de } \\
\text { ferramenta de pesquisa }\end{array}$ & 1 & 4 & 15 & 3 & 6 & 3 & 5 & 37 & $93 \%$ \\
\hline $\begin{array}{l}\text { Informações quanto as } \\
\text { suas competências }\end{array}$ & 1 & 3 & 15 & 4 & 5 & 2 & 2 & 32 & $80 \%$ \\
\hline $\begin{array}{l}\text { Divulgação de horários } \\
\text { de atendimento ao } \\
\text { público }\end{array}$ & 1 & 4 & 11 & 3 & 6 & 3 & 1 & 29 & $73 \%$ \\
\hline $\begin{array}{l}\text { Informações relativas } \\
\text { aos repasses e } \\
\text { transferências de } \\
\text { recursos financeiros }\end{array}$ & 1 & 3 & 9 & 4 & 6 & 3 & 2 & 28 & $70 \%$ \\
\hline $\begin{array}{l}\text { Informações gerais } \\
\text { para acompanhamento } \\
\text { de programas, ações, } \\
\text { projetos e obras }\end{array}$ & 1 & 4 & 11 & 2 & 6 & 3 & 1 & 28 & $70 \%$ \\
\hline $\begin{array}{l}\text { Orientação sobre } \\
\text { os procedimentos } \\
\text { para solicitação de } \\
\text { informação }\end{array}$ & 1 & 1 & 12 & 3 & 6 & 3 & 1 & 27 & $68 \%$ \\
\hline $\begin{array}{l}\text { Disponibilização de } \\
\text { "respostas e perguntas" } \\
\text { mais frequentes da } \\
\text { sociedade }\end{array}$ & 1 & 2 & 10 & 3 & 3 & 2 & 1 & 22 & $55 \%$ \\
\hline $\begin{array}{l}\text { Informação } \\
\text { transparente, clara e } \\
\text { em linguagem de fácil } \\
\text { compreensão }\end{array}$ & 0 & 3 & 9 & 2 & 4 & 2 & 1 & 21 & $53 \%$ \\
\hline $\begin{array}{l}\text { Serviço de Informações } \\
\text { ao Cidadão (SIC) }\end{array}$ & 1 & 1 & 10 & 1 & 6 & 1 & 1 & 21 & $53 \%$ \\
\hline $\begin{array}{l}\text { Conteúdo acessível a } \\
\text { pessoas com deficiência }\end{array}$ & 0 & 2 & 8 & 3 & 3 & 2 & 2 & 20 & $50 \%$ \\
\hline
\end{tabular}

* I = Centro Ocidental; II = Centro Oriental; III = Metropolitana; IV = Nordeste; $\mathrm{V}=$ Noroeste; $\mathrm{VI}=$ Sudeste; $\mathrm{VII}=$ Sudoeste.

Fonte: Elaborada a partir de dados da pesquisa (2014). 
Com base na Tabela 10, percebe-se que todos os municípios disponibilizaram informações sobre suas estruturas organizacionais, bem como endereços e telefones para contato. O terceiro indicador apresentado - permissão para gravação de relatórios eletrônicos - foi satisfeito em quase todos os casos, não sendo permitido salvar os arquivos em somente um dentre todos os municípios analisados.

Em relação às despesas, apenas dois municípios deixaram de disponibilizar informações: Rio Grande e Santana do Livramento. Quanto às licitações, editais e demais contratos celebrados, foram encontrados dados em $93 \%$ dos portais eletrônicos consultados.

A disponibilização de ferramenta de pesquisa ocorreu em quase todos os casos, com 93\% do total de municípios. Vale ressaltar sua importância nos portais eletrônicos, posto que a ferramenta foi amplamente utilizada como facilitadora no processo de coleta de dados do presente estudo. Em relação às competências existentes nas prefeituras, o percentual de divulgação caiu para $80 \%$, e aos horários de atendimento ao público, $73 \%$, sendo disponibilizados por 29 dos 40 municípios analisados.

Ainda, segundo informações da Tabela 10, em 28 municípios foram encontradas informações acerca de repasses e transferências de recursos financeiros. Os "dados gerais" para acompanhamento de programas, ações, projetos e obras a que se refere a LAI foram considerados satisfeitos nos casos em que foram disponibilizados ou documentos que trouxessem informações detalhadas, ou notícias específicas sobre o assunto. Em 70\% dos casos encontrou-se evidências que possibilitaram o acompanhamento dos principais programas, projetos e obras em desenvolvimento.

Conforme a LAI, o acesso à informação compreende o direito do cidadão de obter orientações sobre procedimentos para solicitar e acompanhar os pedidos de informação que lhe interessar, bem como o local onde poderá encontrá-la ou obtê-la (BRASIL, 2011). Pode-se observar que, em muitos casos, a população não tem recebido tais orientações, tendo em vista que 
apenas $68 \%$ dos municípios estão agindo conforme rege a lei. Nos demais casos, o cidadão não vem sendo orientado quanto ao que é necessário fazer para obter as informações que a ele devem ser divulgadas por direito.

No estudo de Viana et al. (2013) comprovou-se a inexistência da opção de perguntas frequentes no portal eletrônico do município de Manaus. Já no RS, conforme dados da Tabela 10, pouco mais da metade da amostra (55\%) divulgou perguntas frequentes da sociedade, como estipulado na LAI. Quanto às exigências de informação transparente, clara e em linguagem de fácil compreensão, foram consideradas atendidas sempre que os municípios dispuseram as informações necessárias, e, além disso, de forma organizada, em que o acesso fosse facilitado e inteligível, a fim de que todos pudessem compreendê-las. Nota-se, ainda, que se está longe do ideal, pois apenas 53\% da amostra pontuou nesse quesito. Isto é, 19 municípios ou não apresentaram as informações que deveriam, ou o fizeram de forma inadequada, assim como verificado por Leite Filho, Andrade e Colares (2014), que obtiveram resultados semelhantes nos municípios de Minas Gerais, nos quais a maior parte das informações foi considerada defasada ou incompleta, denotando que os mesmos não estão prestando informações completas e tempestivas como rege a lei.

Por fim, 21 municípios apresentaram área específica para o cidadão manifestar suas dúvidas, obter e solicitar informações: o Serviço de Informações ao Cidadão (SIC). Além disso, metade dos portais eletrônicos disponibilizou acesso facilitado a pessoas com algum tipo de deficiência visual: foram oferecidas opções de fonte (maior/menor) e regulagem de contraste. Já no estudo de Silva (2013) não foram encontrados quaisquer indícios de acessibilidade nos municípios mato-grossenses. Esses resultados são preocupantes, pois, como mencionado por Viana et al. (2013), a falta de acessibilidade é uma barreira ao alcance de toda a população.

Como observado por Cruz et al. (2012), é imprescindível que as informações divulgadas acerca dos resultados obtidos pela gestão pública sejam claras e tempestivas, e disponibilizadas de forma acessível ao cidadão 
em diversos meios de comunicação, principalmente na internet. A partir da Tabela 10 pode-se inferir que, assim como observado pelos autores, os níveis de transparência ainda são baixos quando considerada a importância da divulgação de informações exigidas pela LAI.

\section{Considerações Finais}

Esta pesquisa buscou verificar o grau de transparência dos municípios do Estado do Rio Grande do Sul com mais de 50 mil habitantes, por meio da análise do cumprimento das exigências das leis de Responsabilidade Fiscal e de Acesso à Informação. Para isso, foram analisadas as informações disponibilizadas no Portal da Transparência dos 40 municípios pertencentes à amostra, de acordo com indicadores preestabelecidos.

Diante dos dados da pesquisa pode-se mencionar que muitas informações exigidas pelas leis em questão não têm sido divulgadas pelos municípios, que apresentaram baixos níveis de transparência em diversos quesitos. Além disso, muitas informações, quando disponibilizadas, não foram consideradas suficientes, claras e tempestivas, prejudicando o processo de participação popular e controle social.

Com base nos dados de estatística descritiva da amostra, observou-se que o Índice de Conformidade Geral Médio do Estado foi inferior a 70\%, sendo ainda menor em relação à LRF $(54,33 \%)$, e pouco superior se tratando da LAI (76,50\%). Esses resultados podem ser considerados positivos quando comparados com os obtidos por Silva (2013) nos municípios do Mato Grosso, porém não podem ser tidos como satisfatórios, se analisadas todas as informações que não estão sendo divulgadas ao cidadão.

Dentre as sete mesorregiões analisadas, a que apresentou menor nível de transparência foi a Sudoeste Rio-Grandense, com IC Geral Médio de 51,11\%. Já o maior número de informações disponibilizadas no Portal Transparência ocorreu na Mesorregião Sudeste Rio-Grandense, que obteve 
IC Geral Médio de 75,56\%. Ressalta-se, ainda, as disparidades encontradas na maior Mesorregião do Estado, a Metropolitana de Porto Alegre. Assim como alguns municípios da região apresentaram ótimos níveis de transparência, outros obtiveram desempenho insatisfatório, tornando o IC Geral Médio da região pouco abaixo da média do RS.

Em relação à LRF, as informações menos divulgadas pelos municípios foram o Relatório de Prestação de Contas, bem com seu Parecer Prévio, e as datas de audiências públicas quadrimestrais para avaliação das metas fiscais. Quanto à LAI, os quesitos menos encontrados nos portais eletrônicos foram conteúdo acessível a pessoas com deficiência, Serviço de Informações ao Cidadão (SIC) e informações transparentes, claras e em linguagem de fácil compreensão.

Pode-se inferir que os municípios rio-grandenses não estão atendendo à totalidade das exigências contidas nas leis de Responsabilidade Fiscal e de Acesso à Informação, apresentando, em muitos casos, níveis insatisfatórios de divulgação de informações compulsórias, de direito dos cidadãos. Ainda, quando divulgadas, algumas informações não têm sido claras, tempestivas, nem pormenorizadas, como exigem as leis.

Como os aspectos estudados se referem a itens de obrigatório cumprimento, tanto pela LRF quanto pela LAI, é preocupante que, mesmo em municípios com mais de 50 mil habitantes, e que tem uma capacidade econômica relevante, sejam encontrados níveis de conformidade ainda distantes do cumprimento integral. Esta é uma reflexão que remete para a falta de transparência que, muitas vezes, se alimenta da falta de maior participação da população na definição de políticas públicas e na fiscalização dos atos de gestão.

Sendo assim, sugere-se que haja maior fiscalização quanto ao cumprimento das leis em questão, e que seja estabelecido modelo padrão de disponibilização de informações na internet, haja vista que cada município o faz de forma particular, dificultando o acesso do cidadão. Como sugestão 
para estudos futuros, propõe-se que seja investigada no Rio Grande do Sul a relação entre o grau de desenvolvimento socioeconômico dos municípios e seus respectivos índices de transparência.

\section{Referências}

BARDIN, L. Análise de conteúdo. Lisboa: Edições 70, 2006.

BRASIL. Lei $n^{\circ} 4.320$, de 17 de março de 1964. Estatui normas gerais de direito financeiro para elaboração e controle dos orçamentos e balanços da União, dos Estados, dos Municípios e do Distrito Federal. Disponível em: <http://www.planalto. gov.br/ccivil_03/leis/14320.htm>. Acesso em: $1^{\circ}$ jun. 2014.

. Constituição da República Federativa do Brasil de 1988. Dispõe sobre princípios, direitos e deveres dos cidadãos brasileiros. Disponível em: <http://www.planalto.gov. br/ccivil_03/Constituicao/Constituicao.htm>. Acesso em: $1^{\circ}$ jun. 2014.

Lei Complementar $n^{\circ}$ 101, de 04 de maio de 2000. Lei de Responsabilidade Fiscal - LRF. Estabelece normas de finanças públicas voltadas para a responsabilidade na gestão fiscal e dá outras providências. Disponível em: <http://www.planalto. gov.br/ccivil_03/leis/lcp/lcp101.htm>. Acesso em: 3 ago. 2014.

. Lei Complementar $n^{\circ}$ 131, de 27 de maio de 2009. Lei da Transparência. Acrescenta dispositivos à Lei Complementar no 101, de 4 de maio de 2000. Disponível em: <http://www3.dataprev.gov.br/SISLEX/paginas/43/2009/131.htm>. Acesso em: 3 ago. 2014.

Lei $n^{\circ} 12.527$, de 18 de novembro de 2011. Lei de Acesso à Informação LAI. Disponível em: <http://www.planalto.gov.br/ccivil_03/_ato2011-2014/2011/lei/ 112527.htm>. Acesso em: 3 ago. 2014.

CONSELHO FEDERAL DE CONTABILIDADE (CFC). Normas Brasileiras de Contabilidade - Contabilidade Aplicada ao Setor Público: NBCs T 16.1 a 16.11. Brasília: Conselho Federal de Contabilidade, 2012. Disponível em: <http://portalcfc. org.br/wordpress/wp-content/uploads/2013/01/Setor_P\%C3\%BAblico.pdf>. Acesso em: $1^{\circ}$ jun. 2014. 
CONTROLADORIA GERAL DA UNIÃO (CGU). Acesso à informação pública: uma introdução à Lei n ${ }^{\circ} 12.527$, de 18 de novembro de 2011. Disponível em: <http:// www.cgu. gov.br/Publicacoes/CartilhaAcessoaInformacao/index.asp $>$. Acesso em: 6 abr. 2014.

CRUZ, C. F. et al. Transparência da Gestão pública municipal: um estudo a partir dos portais eletrônicos dos maiores municípios brasileiros. Revista de Administração Pública, Rio de Janeiro, v. 46, n. 1, jan./fev. 2012.

GIL, A. C. Métodos e técnicas de pesquisa social. 6. ed. São Paulo: Atlas, 2008.

INSTITUTO BRASILEIRO DE GEOGRAFIA E ESTATÍSTICA (IBGE). Censo 2010 - Municípios do Rio Grande do Sul. 2010. Disponível em: <http://www.cidades. ibge. gov.br/xtras/uf.php?lang=\&coduf=43\&search=rio-grande-do-sul $>$. Acesso em: 3 ago. 2014.

KIERKEGAARD, S. Open access to public documents - More secrecy, less transparency! Computer Law \& Security Review, v. 25, n. 1, p. 3-27, 2009.

KOHAMA, H. Contabilidade pública: teoria e prática. 10. ed. São Paulo: Atlas, 2009. KRAEMER, M. E. P. O impacto da contabilidade no sistema de gestão fiscal. Revista CRCSG \&̊ Você, Florianópolis, v. 3, n. 6, p. 19-31, 2003.

LEITE FILHO, G. A.; ANDRADE, I. C. F.; COLARES, A. F. V. Transparência da gestão fiscal pública: um estudo a partir dos portais eletrônicos dos maiores municípios do Estado de Minas Gerais. In: CONGRESSO USP CONTROLADORIA E CONTABILIDADE, 11., 2014, São Paulo. Anais... São Paulo, SP: FEA; USP, 2014.

RAUPP, F. M.; BEUREN, I. M. Metodologia da pesquisa aplicável às ciências sociais. In: BEUREN, I. M. (Org.). Como elaborar trabalhos monográficos em contabilidade: teoria e prática. 3. ed. São Paulo: Atlas, 2013. p. 76-97.

SILVA, A. L. Evidenciação de informações nas páginas web de prefeituras municipais mato-grossenses: uma análise de aderência à Lei de Responsabilidade Fiscal e à Lei de Acesso à Informação. 2013. 116 f. Dissertação (Mestrado em Ciências Contábeis) - Universidade do Vale do Rio dos Sinos, Curso de Pós-Graduação em Ciências Contábeis, São Leopoldo, 2013.

SILVA, L. M.; BIANCHI, M.; VENDRUSCOLO, M. I. Contabilidade no setor público: gestão, controle e apoio às políticas de desenvolvimento. In: HENKIN, Hélio (Org.). Política industrial e internacionalização. Porto Alegre: UFRGS; Cegov, 2014. p. $178-199$. 
ANÁLISE DO GRAU DE ADERÊNCIA À LEI DE RESPONSABILIDADE FISCAL E À LEI DE ACESSO À INFORMAÇÃO NOS MUNICÍPIOS DO ESTADO DO RIO GRANDE DO SUL COM MAIS DE 50 MIL HABITANTES

SILVA, L. M. Contabilidade governamental: um enfoque administrativo da nova contabilidade pública. 9. ed. São Paulo: Atlas, 2011.

TEIXEIRA, E. B. A análise de dados na pesquisa científica: importância e desafios em estudos organizacionais. Revista Desenvolvimento em Questão, Ijuí, v. 1, n. 2, p. 177-201, jul./dez. 2003.

VIANA, C. C. et al. Avaliação da aderência aos critérios internacionais transparência para a divulgação e apresentação das contas públicas municipais. Revista Ambiente Contábil, Natal: UFRN, v. 5, n. 1, p. 152-178, jan./jun. 2013. 